\title{
PROJETO TOCANDO ÁTOMOS
}

\author{
MORAES, Jéssica Fernanda Marques ${ }^{1}$ \\ GONÇALVES, Karen Karine ${ }^{2}$ \\ BORGES, Gabriela Ramos 3 \\ FERREIRA, Luiz Guilherme Fernandes ${ }^{4}$ \\ ARAÚJO, Sérgio Carvalho de 5
}

RESUMO: A formação de um cidadão com deficiência visual exige adaptações e práticas que sejam capazes de oferecer um ensino inclusivo. O Projeto Tocando Átomos tem como objetivo proporcionar acesso às crianças e adolescentes nas escolas, para que elas desenvolvam seus atributos com integridade. Trazendo maior clareza e conhecimento na disciplina de química, através de atividades que os próprios professores podem incluir em seu plano de ensino pedagógico. Com a ideia de expor todo o projeto na Casa da Ciência e Cultura de Campo Grande da Universidade Federal de Mato Grosso do Sul, todos os trabalhos e modelos confeccionados são de autoria do grupo PETQuímica.

PALAVRAS-CHAVE: Educação; Ensino de Química; Inclusão; Extensão; Adaptação.

\section{PROJECT TOUCHING ATOMS}

ABSTRACT: The education of blind citizens requires adaptation and practices that can offer an inclusive schooling. The Touching Atoms Project seeks to provide access to the children and teenagers in schools, with more clarity and knowledge about chemistry, through activities that the teachers can include

\footnotetext{
${ }^{1}$ Egressa do grupo PET Química/UFMS (Universidade Federal de Mato Grosso do Sul). E-mail: jeeh.feer.nanda@hotmail.com

${ }^{2}$ Egressa do grupo PET Química/UFMS (Universidade Federal de Mato Grosso do Sul). E-mail: karenkarine86@gmail.com

${ }^{3}$ Egressa do grupo PET Química/UFMS (Universidade Federal de Mato Grosso do Sul). E-mail: ramos_gabriela@ufms.br

${ }^{4}$ Integrante do grupo PET Química/UFMS (Universidade Federal de Mato Grosso do Sul). E-mail: luiz.guilherme@ufms.br

${ }^{5}$ Tutor egresso do grupo PET Química/UFMS (Universidade Federal de Mato Grosso do Sul). E-mail: sergio.carvalho@ufms.br
} 
in their lesson plan. With the intention to expose the work in the House of Science and Culture in Campo Grande on the Federal University of Mato Grosso do Sul, all the material and the framework molecular models are authored by the PET-Química group.

KEYWORDS: Education; Chemistry teaching; Inclusion; Extension; Adaptation.

\section{INTRODUÇÃO}

O compromisso com a formação do cidadão com deficiência visual exige uma prática educacional voltada à compreensão da realidade social, dos direitos e das responsabilidades em relação à sua vida pessoal e comunitária (Tim, Maricato, Ferreira, Lima, \& Aráoz, 2011). Já está mais do que claro de que há necessidade de estudos que sejam relacionados a educação inclusiva na formação dos docentes, e pouco se tem em relação ao estudo de química. Partindo disto, o projeto tem uma iniciativa para que os discentes de Química, seja de licenciatura, bacharelado ou engenharia, ampliem a maneira com a qual compreendem seus conteúdos.

O professor hoje tem o papel de compreender a educação como exercício de cidadania, e o que era repercutido como algo desconhecido e sujeito a discriminação, no momento é encarado como um desafio principalmente para os educandos. Desenvolvendo métodos que venham garantir a integração dos alunos com baixa ou nenhuma visão. Para que todas as crianças tenham esse direito garantido através da Constituição Federal, de 1988, e ainda duas leis que regulamentam e complementam a do direito à Educação: o Estatuto da Criança e do Adolescente (ECA), de 1990; e a Lei de Diretrizes e Bases da Educação (LDB) de 1996-LDBE - Lei no 9.394 de 20 de Dezembro de 1996, estabelece as diretrizes e bases da educação nacional, Art. 30 O ensino será ministrado com base nos seguintes princípios: XIII garantia do direito à educação e à aprendizagem ao longo da vida. (Incluído pela Lei no 13.632 , de 2018).

Outrossim, é importante ressaltar que a constituição de um grupo de alunos vinculado a um curso de graduação para desenvolver ações de

Revista Eletrônica do Programa de Educação Tutorial - Três Lagoas/MS - v. 3, n. 3, Outubro (2021). 
ensino, pesquisa e extensão sob a orientação por um professor tutor visa oportunizar aos estudantes participantes a possibilidade de ampliar a gama de experiências em sua formação acadêmica e cidadã. Assim, o Programa de Educação Tutorial objetiva complementar a perspectiva convencional de educação escolar baseada, em geral, em um conjunto qualitativamente limitado de constituintes curriculares.

Em relação à deficiência visual (DV), observa-se que a maior dificuldade para a educação destes alunos é que as propostas educacionais têm como base a visão para percepção e apropriação de conhecimento. Porém, faz-se necessário quebrar esta limitação mostrando-Ihes que além da visão existem outros caminhos de comunicação que tornam possível o ensino para deficientes visuais, como o tato, a fala, a escrita e até mesmo o paladar. Posto isso, torna-se possível a quebra do paradigma de "ter que enxergar para aprender" (CONFORTO e SANTAROSA, 2002).

O Projeto Tocando Átomos busca proporcionar que o acesso à formação inclusiva, seja levado para dentro das escolas, principalmente as públicas, possibilitando ao público alguma oportunidade de experiência, oferecendo várias alternativas para promover maior clareza no conhecimento de química para o ensino médio e fornecer bases para aprimorar a capacitação dos professores, bem como um processo de ensino e aprendizagem para os acadêmicos envolvidos no projeto.

Visando assegurar uma educação inclusiva e de qualidade, a produção de materiais didáticos e modelos neste projeto buscou sempre o baixo custo para uma melhor adesão e acessibilidade, a fim de diminuir os baixos níveis de aprendizagem de química e a discriminação. Essa oportunidade é essencial para que ações inclusivas sejam cada vez mais incorporadas, tanto nas escolas como nas universidades, para que as barreiras sejam eliminadas.

Esta atividade contribuirá para o atingimento dos ODS/ONU através as seguintes práticas:

4 - Educação de Qualidade

10 - Redução das Desigualdades

Revista Eletrônica do Programa de Educação Tutorial - Três Lagoas/MS - v. 3, n. 3, Outubro (2021). 
Após a obtenção de um resultado satisfatório dos processos, o projeto deverá ir a campo para testes e arredondamentos finais. Devido ao momento pandêmico infelizmente ainda não foi possível testar presencialmente os modelos criados. Logo, proporcionará o primeiro contato dos alunos com a didática criada. De acordo com os métodos avaliativos, será decidido em grupo quais mudanças devem ser realizadas para que o trabalho seja realizado de maneira eficaz, eficiente e efetiva, através das devolutivas que serão obtidas dos seus participantes.

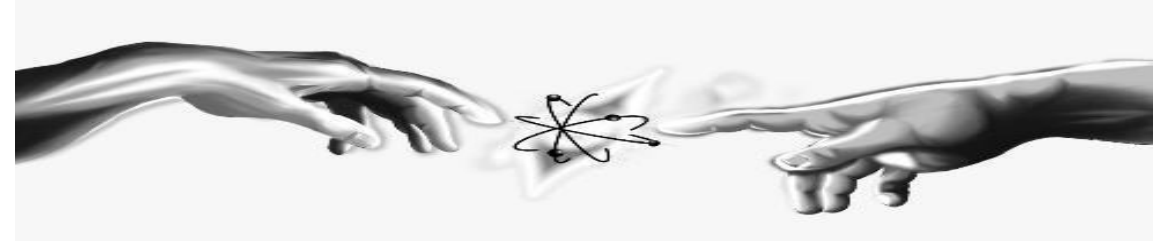

Figura 1 - Logo Projeto Tocando Átomos. Fonte: Acervo PET Química, 2020.

\section{METODOLOGIA}

O Projeto teve seu início com uma pesquisa teórica voltada à inserção da problemática em questão: deficiência visual e ensino de química. Foram realizadas visitas ao Instituto de Cegos de Campo Grande e ao CAP-DV/MS da SED/MS mais ainda é necessário um maior aprofundamento teórico dos petianos participantes da atividade.

Para dar início ao conteúdo de Química a ser relacionado pelo projeto, foi elaborada uma lista dos tópicos a serem trabalhados em duas apostilas, que posteriormente foram transcritas e impressas em Braile pelo Centro de Apoio Pedagógico ao Deficiente Visual (CAP-DV/MS).

1. Química Atomística:

i) Partículas do átomo: Elétrons, prótons e nêutrons. 
ii) Número atômico e Número de massa.

iii) Isótopos, Isóbaros e Isótonos.

iv) Modelos atômicos: Dalton, Thompson, Rutherford e Bohr.

2. Química Orgânica:

i) Características Gerais das Moléculas Orgânicas.

II) Características do Átomo de Carbono.

III) Representação das Cadeias Carbônicas.

IV) Classificação dos Carbonos.

V) Classificação das Cadeias Carbônicas.

VI) Compostos Aromáticos.

VII) Introdução às Funções Orgânicas.

VIII) Nomenclatura IUPAC.

A Apostila Teórica de Química Atomística e a Tabela Periódica, foram os primeiros a ter seu conteúdo transcrito para Braile, pelo Centro De Apoio Pedagógico ao Deficiente Visual (CAP-DV/MS), através do apoio do transcritor e adaptador Dirceu Aparecido Borges em Campo Grande, Mato Grosso do Sul. 


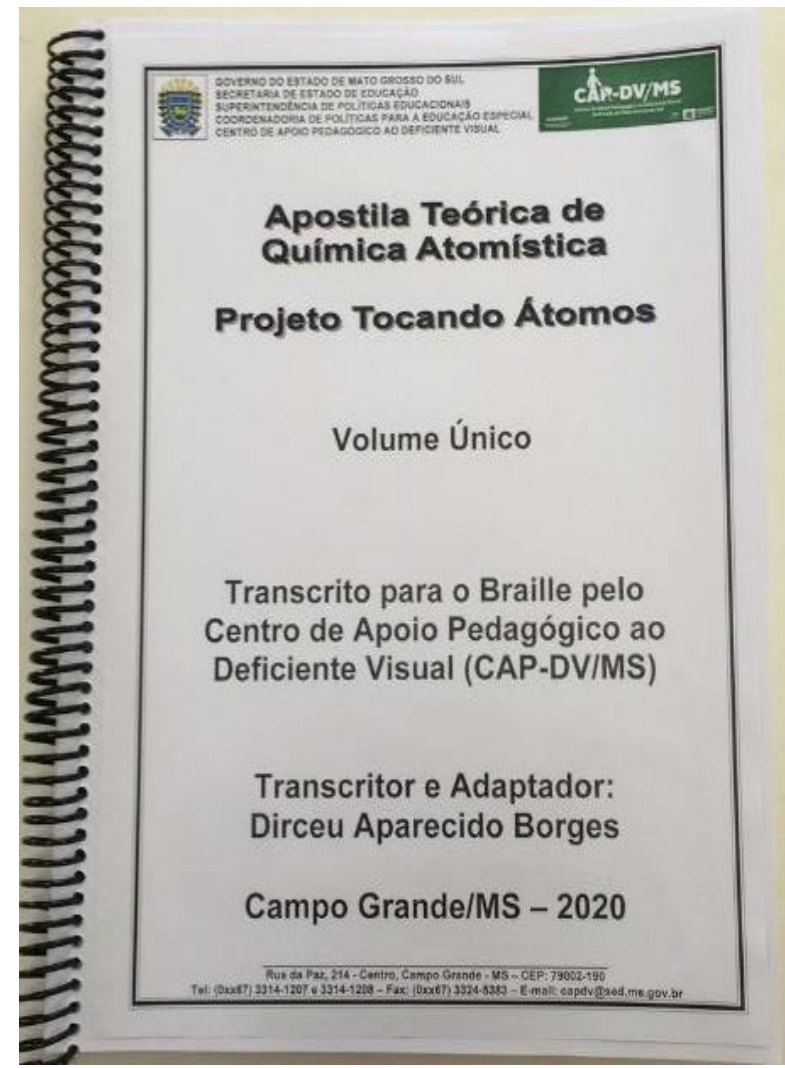

Figura 2 - Apostila de Química Atomística. Fonte: Acervo PET Química, 2020.

O projeto ainda tem como objetivo transcrever e imprimir a segunda apostila de Química Orgânica, que está com conteúdo finalizado. Ambas se encontram disponíveis no link ${ }^{6}$ do drive.

6

https://drive.google.com/drive/folders/1gVIcfZqXrFl87d4CJApseTUJXk1Jsc0j?usp=s haring

Revista Eletrônica do Programa de Educação Tutorial - Três Lagoas/MS - v. 3, n. 3, Outubro (2021).

ISSN 2675 - 1003 


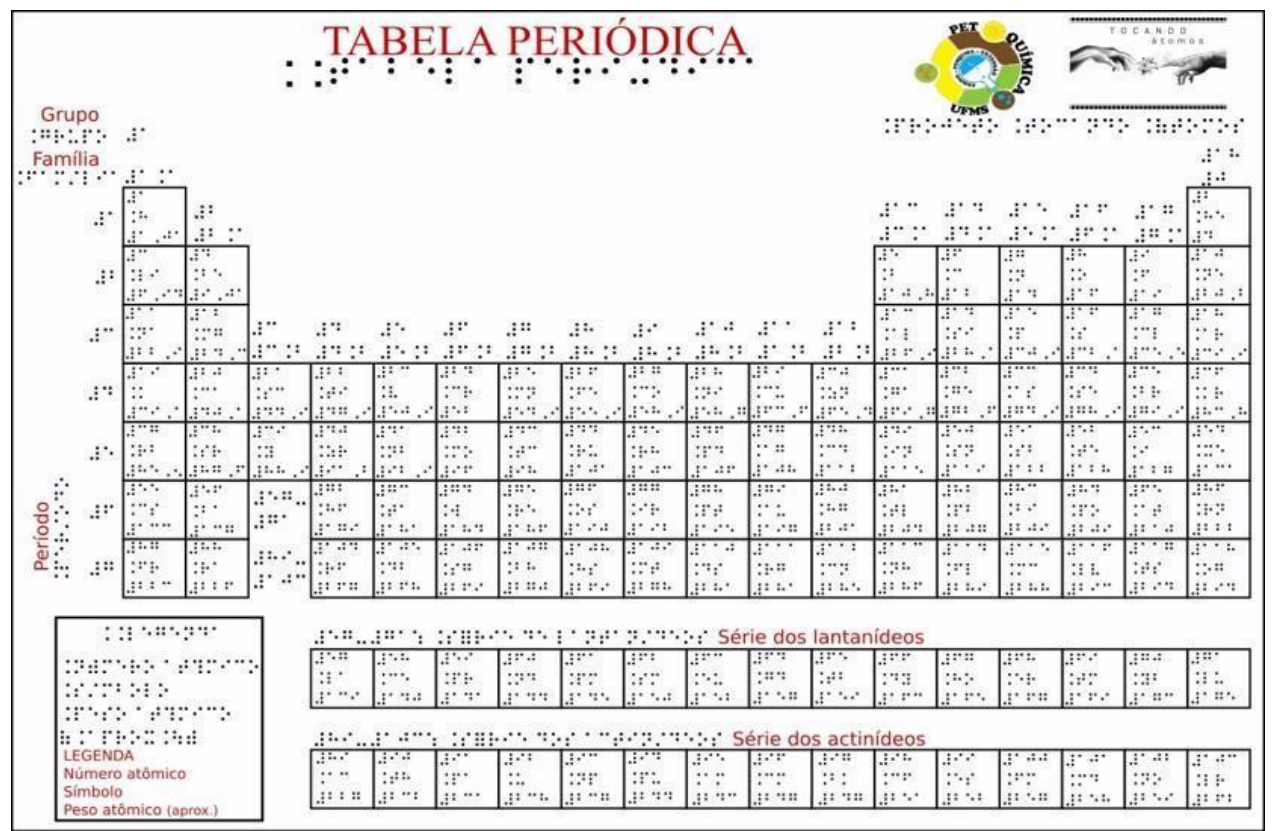

Figura 3 - Tabela Periódica em Braile. Fonte: Acervo PET Química, 2020

Posteriormente, deu-se início aos kits moleculares, sendo dois kits moleculares comercial e um kit molecular impresso em 3D, cujo este foi confeccionado e impresso no INQUI, Instituto de Química, da Universidade Federal de Mato Grosso do Sul. Os kits moleculares comerciais foram adaptados com cola 3D, formando um relevo na superfície das esferas. Cada esfera representa um átomo e a adaptação com cola 3D foi feita nos átomos mais utilizados para o ensino de química, são esses: Carbono, Oxigênio, Nitrogênio, Hidrogênio e os Halogênios (Figura 4).

O Kit Molecular impresso em 3D foi o último material a ficar pronto, possui 52 peças no total, e suas adaptações diferem das do kit molecular comercial (Figura 5 e 6 ). Todos os kits possuem guia para uso e com a identificação de cada peça, possibilitando o uso das duas em aula e uma melhor adaptação para ensino.

Revista Eletrônica do Programa de Educação Tutorial - Três Lagoas/MS - v. 3, n. 3, 


\section{Guia para o Kit Molecular Comercial}

- Manusear com cuidado, pois a cola 3D descola com facilidade.

- É importante refazer os relevos, caso o mesmo se descole da peça

- Guardar em local seco.

- Não manusear o material com as mãos sujas, molhadas ou com as mãos molhadas de álcool em gel.

- Ser cauteloso com o Kit Molecular, evite perda e danos. $\ddagger$

\begin{tabular}{|c|c|c|c|c|c|c|}
\hline \multicolumn{7}{|c|}{ Identificação das peças } \\
\hline Elemento & Orificios & Ângulo & $\begin{array}{l}\text { Cor da } \\
\text { Peça }\end{array}$ & $\begin{array}{c}\text { Cola 3D } \\
\text { (cor) }\end{array}$ & $\begin{array}{l}\text { DIAM } \\
(\mathrm{mm})\end{array}$ & Relevo \\
\hline $\begin{array}{c}\text { Carbono } \\
\text { (C) }\end{array}$ & 1 & $\begin{array}{c}109^{\circ} \\
\text { Tetraédrico }\end{array}$ & Preta & Branco & 23 & 3 círculos \\
\hline \multirow{2}{*}{$\begin{array}{l}\text { Nitrogênio } \\
(\mathrm{N})\end{array}$} & 3 & $\begin{array}{c}107^{\circ} \\
\text { Piramidal }\end{array}$ & \multirow{2}{*}{ Azul } & \multirow{2}{*}{ Amarelo } & \multirow{2}{*}{23} & \multirow{2}{*}{$\begin{array}{c}1 \text { bola e } 3 \\
\text { pingos }\end{array}$} \\
\hline & 4 & $\begin{array}{c}109^{\circ} \\
\text { Tetraédrico }\end{array}$ & & & & \\
\hline $\begin{array}{l}\text { Oxigênio } \\
\text { (O) }\end{array}$ & 2 & $\begin{array}{c}105^{\circ} \\
\text { Angular }\end{array}$ & Vermelha & Amarelo & 23 & $\begin{array}{c}\text { Cobrir com } \\
\text { pingos }\end{array}$ \\
\hline $\begin{array}{c}\text { Halogênio } \\
(\mathrm{Cl}, \mathrm{F})\end{array}$ & 1 & - & Verde & Branca & 17 & $\begin{array}{l}2 \text { círculos } \\
\text { transversais }\end{array}$ \\
\hline $\begin{array}{c}\text { Hidrogênio } \\
(\mathrm{H})\end{array}$ & 1 & - & Branca & nada & 17 & nada \\
\hline
\end{tabular}

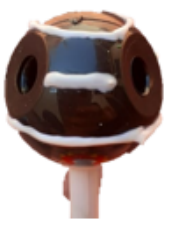

Carbono

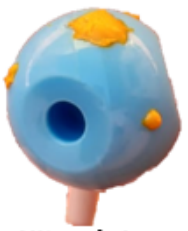

Nitrogênio

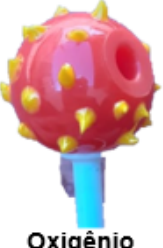

Oxigênio

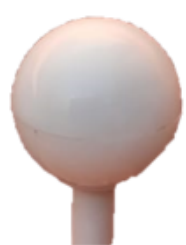

Halogênio

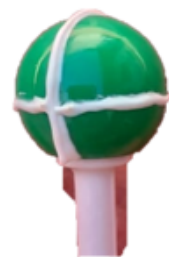

Hidrogênio

Figura 4- Guia para Kit Molecular. Fonte: Acervo PET Química 


\section{Guia para o Kit Molecular impresso em 3D}

- Guardar em local seco.

- Não manusear o material com as mãos sujas, molhadas ou com as mãos molhadas de álcool em gel.

- Ser cauteloso com o manuseio do Kit Molecular, evite perda e danos.

\begin{tabular}{|c|c|c|c|c|c|}
\hline \multicolumn{6}{|c|}{ Identificação das Peças } \\
\hline Elemento & Cor & Orifício & Ângulo & $\begin{array}{l}\text { DIAM } \\
(\mathrm{mm})\end{array}$ & Relevo \\
\hline $\begin{array}{l}\text { Carbono } \\
\text { (C) }\end{array}$ & Preto & 4 & $109^{\circ}$ Tetraédrico & 23 & Ferradura \\
\hline $\begin{array}{l}\text { Hidrogênio } \\
(\mathrm{H})\end{array}$ & Branco & 1 & - & 17 & Nada \\
\hline $\begin{array}{l}\text { Boro } \\
\text { (B) }\end{array}$ & Bege & 3 & $\begin{array}{c}120^{\circ} \text { Trigonal } \\
\text { plano }\end{array}$ & 23 & Círculos \\
\hline \multirow{2}{*}{$\begin{array}{l}\text { Nitrogênio } \\
(\mathrm{N})\end{array}$} & \multirow{2}{*}{ Azul } & 3 & $107^{\circ}$ Piramidal & \multirow{2}{*}{23} & \multirow[t]{2}{*}{ Hexágonos } \\
\hline & & 4 & $109^{\circ}$ Tetraédrico & & \\
\hline \multirow{2}{*}{$\begin{array}{l}\text { Oxigênio } \\
\text { (O) }\end{array}$} & \multirow{2}{*}{ Vermelho } & 2 & $105^{\circ}$ Angular & \multirow{2}{*}{23} & \multirow{2}{*}{ Estrelas } \\
\hline & & 4 & $109^{\circ}$ Tetraédrico & & \\
\hline \multirow{2}{*}{$\begin{array}{l}\text { Enxofre } \\
\text { (S) }\end{array}$} & \multirow{2}{*}{ Amarelo } & 2 & $105^{\circ}$ Angular & \multirow{2}{*}{23} & \multirow{2}{*}{ Flecha } \\
\hline & & 6 & $90^{\circ}$ Hexagonal & & \\
\hline \multirow{2}{*}{$\begin{array}{c}\text { Fósforo } \\
\text { (P) }\end{array}$} & \multirow{2}{*}{ Roxo } & 5 & $\begin{array}{c}90^{\circ} / 120^{\circ} \mathrm{Tri} \\
\text { bipiramidal }\end{array}$ & \multirow{2}{*}{23} & \multirow{2}{*}{ Triângulo } \\
\hline & & 3 & $107^{\circ}$ Piramidal & & \\
\hline $\begin{array}{l}\text { Halogênio } \\
(\mathrm{Cl}, \mathrm{F})\end{array}$ & Verde & 1 & - & 17 & Pintalgado \\
\hline $\begin{array}{l}\text { Metal } \\
(\mathrm{Na})\end{array}$ & Cinza & 1 & - & 20 & Quadrado \\
\hline $\begin{array}{c}\text { Metal } \\
(\mathrm{Ca}, \mathrm{Mg})\end{array}$ & Cinza & 2 & $105^{\circ}$ Angular & 23 & Quadrado \\
\hline $\begin{array}{l}\text { Metal } \\
(\mathrm{Be})\end{array}$ & Cinza & 2 & $180^{\circ}$ Linear & 23 & Quadrado \\
\hline $\begin{array}{l}\text { Metal } \\
(\mathrm{Al})\end{array}$ & Cinza & 3 & $\begin{array}{c}120^{\circ} \text { Trigonal } \\
\text { Plana }\end{array}$ & 23 & Quadrado \\
\hline $\begin{array}{c}\text { Metal } \\
(\mathrm{Si}, \mathrm{Cu})\end{array}$ & Cinza & 4 & $109^{\circ}$ Tetraédico & 23 & Quadrado \\
\hline Metal & Cinza & 6 & $90^{\circ} \mathrm{Hexagonal}$ & 23 & Quadrado \\
\hline
\end{tabular}

Figura 5- Guia para Kit Molecular impresso 3D. Pg 1. Fonte: Acervo PET Química 


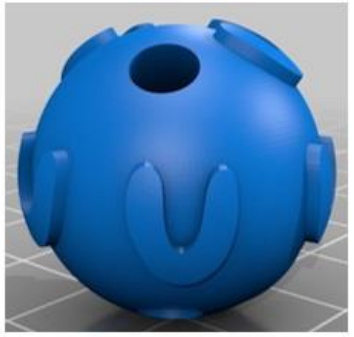

Carbono

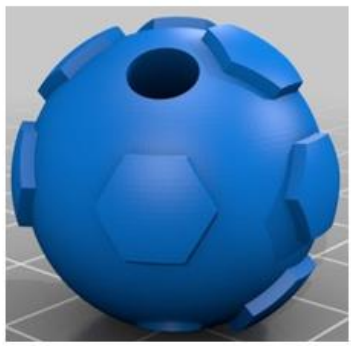

Nitrogênio

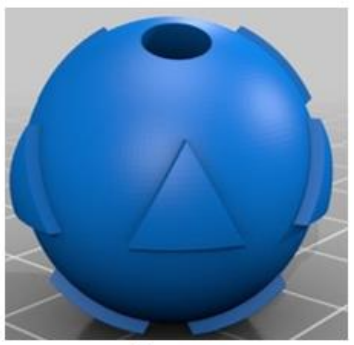

Fósforo

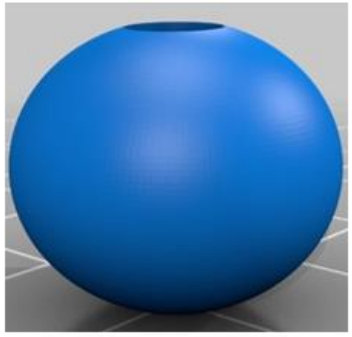

Hidrogênio

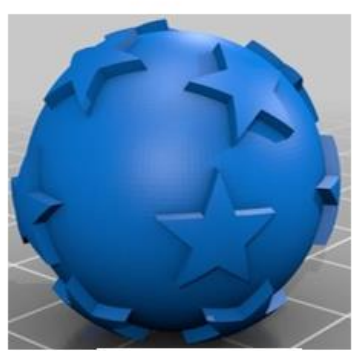

Oxigênio

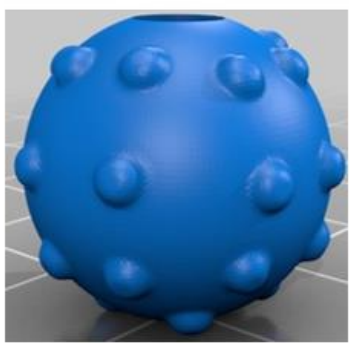

Halogênio

(Cl, F)
(Calogênio

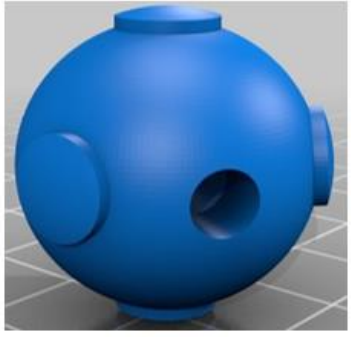

Boro

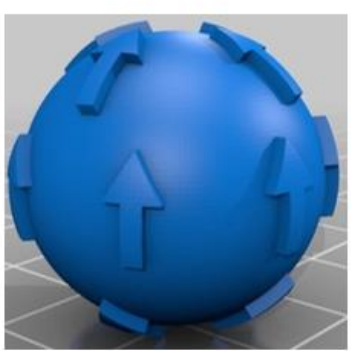

Enxofre

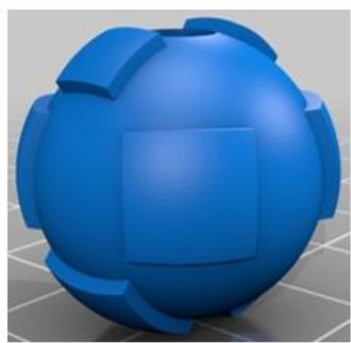

Metal

Figura 6- Guia para Kit Molecular impresso 3D. Pg 2. Fonte: Acervo PET Química 


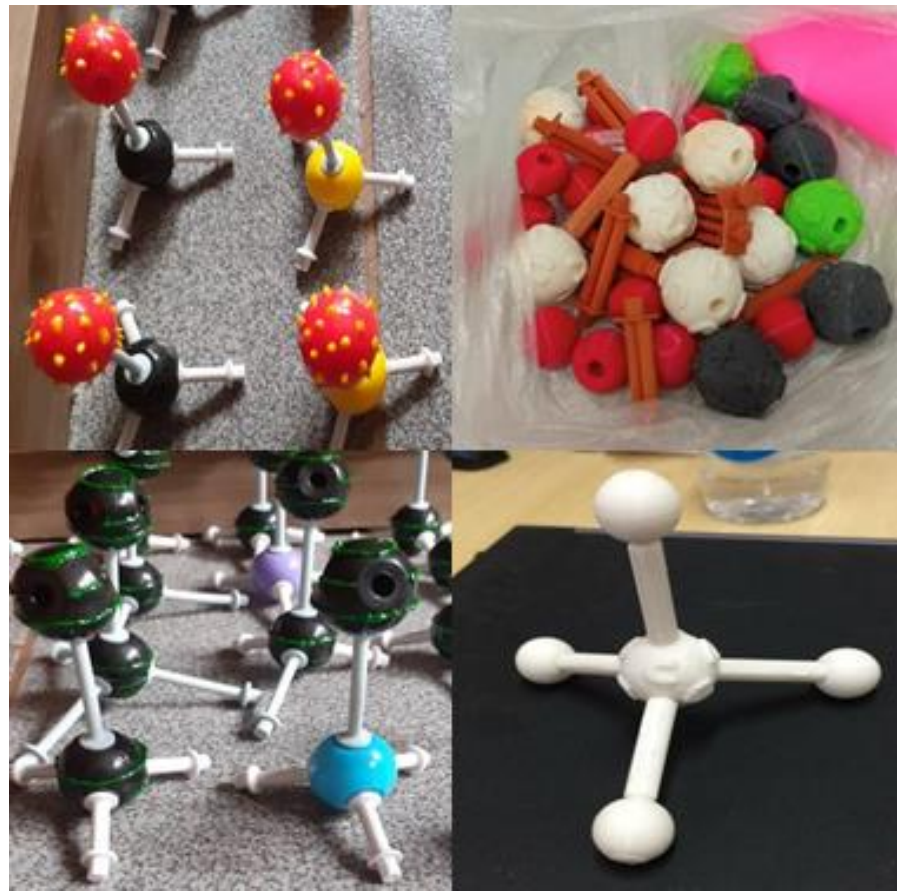

Figura 7 - Kits Molecular adaptado. Fonte: Acervo PET Química

\section{PETCAST}

Acerca do ideal que move o projeto Tocando Átomos, de acessibilidade, políticas inclusivas e democratizar o estudo da Química e ciências, foi criado o PETCast Química, disponível na plataforma Spotify $®$. A fim de mitigar a dificuldade na compreensão dos conteúdos, pois o artifício visual nas aulas de química, é muito utilizado, seja para demonstrações de conformações espaciais, conceitos de orbitais e ligações, o qual, juntamente com uma interpretação do indivíduo, sustenta a sua compreensão sobre a matéria. Sendo assim, a produção de um Podcast, por não possuir atributos visuais, reivindica dos produtores, utilizar o máximo de recursos vocálicos em sua explicação para os ouvintes, o que de forma direta supre o ensino para os deficientes visuais, completando-o. Com isso, a união dos trabalhos em contraste às problemáticas enfrentadas pelos estudantes com os feedbacks e opiniões dos ouvintes, o projeto se moldará, tornando-se mais eficaz no combate as defasagens da matéria e ascende a democracia do estudo da Química e a acessibilidade nos cursos de ensino superior.

Revista Eletrônica do Programa de Educação Tutorial - Três Lagoas/MS - v. 3, n. 3, Outubro (2021). 


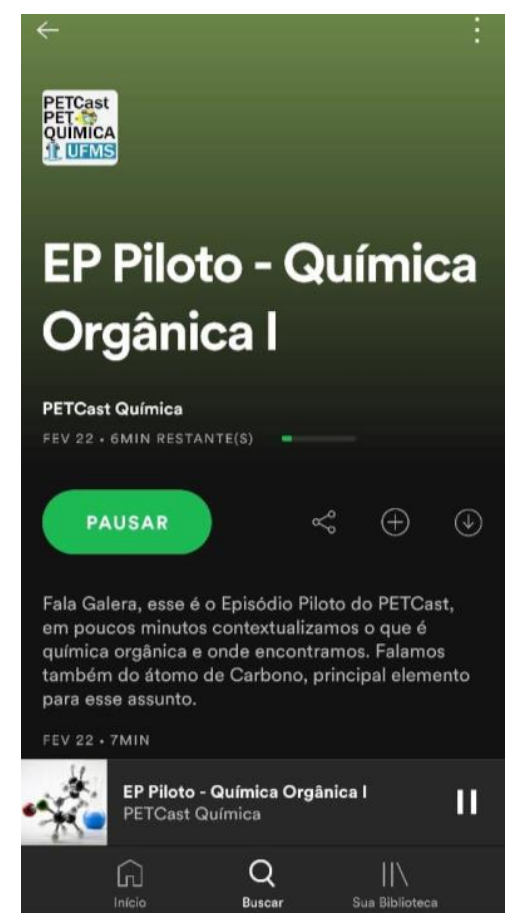

Figura 8 - PrintScreen PETCast no Spotify. Fonte: Acervo PET Química

\section{RESULTADOS E DISCUSSÃO}

O projeto tocando átomos tem a proposta de ensinar conceitos de química para pessoas com baixa ou nenhuma visão, mostrando que não é preciso enxergar para aprender. Pois através dos materiais que fazem parte deste projeto, adaptados com recurso em braile, é possível que os participantes deste projeto possam através de outros sentidos, interpretar as informações que estão adquirindo através da metodologia apresentada.

A visita realizada no Instituto de Cegos de Campo Grande e ao CAPDV/MS da SED/MS, possibilitou a apresentação do kit molecular comercial para um funcionário com deficiência visual total. Cujo este conseguiu diferenciar alguns átomos através do tato, entretanto, o relevo do átomo de nitrogênio e o de carbono ficaram confusos, pois o átomo de carbono possui três círculos e o de nitrogênio, em um primeiro momento, possuía relevos de linhas cruzadas por toda a esfera. Isso dificultou a diferenciação entre os 
átomos, consequentemente, foi alterado o relevo do nitrogênio de linhas cruzadas para três pingos e um círculo preenchido (Figura 4).

O projeto Tocando Átomos além de ter confeccionado os materiais apresentados anteriormente, desenvolveu um projeto paralelo, o PETCast. Cujo este foi apresentado como uma ideia para auxiliar na assimilação dos conceitos teóricos de química. O PETCast, podcast do PET-Química, teve seu episódio piloto publicado em 22 de fevereiro de 2021, os roteiros dos episódios são retirados das apostilas desenvolvidas no projeto tocando átomos, e está disponível em plataformas gratuitas, tais como: Spotify, Google Podcast, etc.

E devido ao momento pandêmico, o grupo ainda não conseguiu apresentar a mudança realizada no kit molecular comercial e o kit molecular impresso em 3D no Instituto de Cegos de Campo Grande e ao CAP-DV/MS da SED/MS, e colocar em práticas nas escolas os modelos e apostilas produzidas. Todavia, espera-se que os alunos poderão desfrutar de uma nova experiência com o conteúdo de química, explorando uma nova maneira de ver o mundo.

\section{CONCLUSÃO}

O conceito inicial foi tomado com intuito de proporcionar uma aprendizagem de modo contextualizado e facilitado, através de materiais inclusivos construídos no projeto, tais como, estruturas de moléculas impressas em 3D com legendas em braile, apostilas em braile e podcast. É de grande interesse para o projeto tocando átomos levar o conhecimento científico com outros olhos e muito mais afundo no ensino de química. 0 projeto tem como iniciativa levar $03 \mathrm{D}$ a sensibilidade já que os alunos participantes não podem ver as dimensões, eles podem sentir através do tato os modelos e estruturas criadas. Assim como os participantes do projeto também são beneficiados, devido a criação e adaptação a este tipo de prática pedagógica.

Revista Eletrônica do Programa de Educação Tutorial - Três Lagoas/MS - v. 3, n. 3, 
No ensino de química há vários conceitos que podem vir a ser adaptados para uma abordagem adequada e criativa, como por exemplo: atomicidade, peso molecular, raios atômicos, cadeias carbônicas, geometria espacial e ligações químicas, onde é possível tocar as estruturas atômicas e as ligações, para que seja possível assimilar a formação dos compostos através dos modelos didáticos. Já na parte de geometria, é possível trabalhar com as estruturas tridimensionais, trabalhando a estrutura geométrica, por exemplo uma forma tetraédrica de um composto de carbono, que pode ser bastante distinguível, como os ligantes em uma molécula e suas diversas propriedades diferentes, sendo compreendidos através de um modelo similar aos já que vem sendo usado para compreensão no curso de orgânica.

Através desses métodos empregados e bem estruturados, o projeto contribui aprimorando ideias novas, contribuindo para outras mais futurística de conhecimento, ou projetos científicos criativos para um novo tipo de estudantes e pesquisadores, onde pode ser incrementado a química computacional que trabalha com sistemas de coordenadas e geometria no espaço através de programas com o auxílio de um comando de voz ampliando para diversas áreas de estudo já que a química também se aprende fora dos laboratórios.

\section{REFERÊNCIAS}

BRASIL. Ministério da Educação. Secretaria de Ensino Superior. Manual de Orientações - PET. Brasília: 2002.

CONFORTO, D. e SANTAROSA, L. M. C. Acessibilidade à Web: Internet para Todos. Revista de Informática na Educação: Teoria, Prática PGIE/UFRGS. 2002

FARIA, Bianka Alves de et al. Ensino de química para deficientes visuais numa perspectiva inclusiva: estudo sobre o ensino da distribuição eletrônica e identificação dos elementos químicos. XI Enpec. Universidade Federal de Santa Catarina, Florianópolis, 
2017. Disponível em: http://www.abrapecnet.org.br/enpec/xienpec/anais/resumos/R0977-1.pdf. Acesso em: 28 abr. 2021

NETO, Washington de Oliveira. A Química Orgânica acessibilizada por meio de kits de modelo molecular adaptados. Universidade de Brasília, 2014.

SIGPET, Campo Grande, MS: Universidade Federal do Mato Grosso do Sul. Planejamento Anual PET Química, 2021. Disponível em: https://drive.google.com/file/d/1jm3PVUPEd5tCt7nsDmqlmkbsa1noCCYm/vi ew?usp=sharing. Acesso em: 28 abr. 2021.

Recebido em: 29 de abril/2021. Publicado em: 31 de outubro/2021. 